\title{
The multi-functional design of child safety seat based on user demands
}

\author{
Shan Ming ${ }^{1}$ a , Kaining Meng ${ }^{2 b \dagger}$, Yuli Zhong ${ }^{3 \mathrm{c}}$ \\ ${ }^{1}$ School of Art and Design, Xihua University, Chengdu, Sichuan, 610039, China \\ ${ }^{2}$ School of Art and Design, Xihua University, Chengdu, Sichuan, 610039, China \\ ${ }^{3}$ School of Art and Design, Xihua University, Chengdu, Sichuan, 610039, China
}

\begin{abstract}
With the improvement in laws and regulations related to children's passenger car safety and full implementation of the two-child policy in China, more and more people are going to be paying attention to child safety seats. Therefore, there will be a huge market for child safety seats of China in the future.

The child safety seats withe the single function of ensuring security can no longer meet the needs of parents and children, the multi-function complex product is becoming the development mainstream gradually. And they even began to pursue appearance molding of products. Most child safety seats on the market have only one function, which can be used in specific scenarios-cars, and after purchase, low frequency of use leads to increased cost. A multi-functional child safety seat is needed to meet the more advanced and increasingly diverse needs of users on this account.

This research not only takes the needs of users in different scenarios as the entry point for the design, takes the multi-function of child safety seats as the subject, and combines the behavior and psychology of the user population of relevant disciplines such as ergonomics and design psychology, but also analyzes the potential and obvious needs of the user population for child safety seats, and optimizes the existing child safety seats on the market from the aspects of child safety seat functions and appearance, so as to further meet the modern higher level of demand for child safety seats.
\end{abstract}

\section{Foreign and domestic research and current situation}

\subsection{Foreign research and current situation}

As a restraints of passenger car, the seat belt can reduce the casualty rate of the accident. The original intention of the invention of the child safety seats and the invention of the car seat belt is completely different. The first child car seat was created in the United States in 1898. It was originally designed to bind children and prevent children from crawling outside and distracting drivers. It was not until the 1960s that the first child safety seat was invented by Leonard Rivkin and applied for a patent in the United States Patent Office, which made.

people pay attention to the safety of child passenger cars. Since then, child safety seats began to develop rapidly, deriving various installation methods, protection methods and child fixation methods.

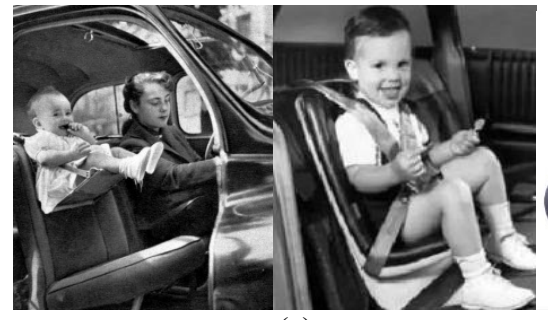

(a)

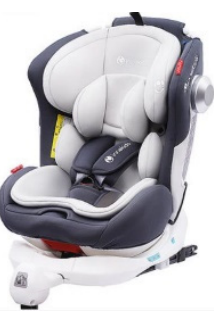

(b)
Figure 1: Former(a) and current(b) child safety seats

The positive development of child safety seat research is inseparable from the laws and regulations concerning child restraint systems successively introduced by various countries. At present, there are more than 90 countries that compulsory use of child restraint system, and have corresponded production and testing standards. Different countries have different standards. Among them, the European Union ECE R44/04 and i-Size (ECE R309) standards are the most stringent in the world, and many countries follow this standard.

\subsection{Domestic research and current situation}

The entire automobile industry in China started relatively late, as is the study of child restraint systems, and the level 
of development is relatively lagging behind developed countries in Europe and America, and is in its infancy. For example, the design of child safety seats is also in the transitional period from the imitation stage to independent research and development. Therefore, the development of child safety seats design in China still has a long way to go.

The development of child safety seats of China is lagging behind. On the one hand, it comes from the late popularity of Chinese cars. It was not until the 1990s that cars began to enter ordinary families, which was 50 to 60 years later than the United States. On the other hand, because the relevant laws and regulations are immature and imperfect, there are no regulations to enforce the use of child restraint systems. The "Restriction System for Child Occupants of Motor Vehicles" is a landmark national standard, which stipulates the rules for children's riding. This standard was not officially implemented until July $1,2012^{[1]}$, but it was not strong enough. The scope is not wide enough, it only involves industry standards, does not touch the relevant regulations and fines of end consumers, and the implementation and enforcement are not satisfactory.

Parents' inadequate attention and misconceptions about child restraint systems are also a major obstacle to the full implementation of child safety seats. according to a 2016 survey report, when children ride in a private car, the proportion of children in the adults' arms (including sitting rear and co-pilot positions) is $50.1 \%$; another $37.6 \%$ of children ride alone (including sitting rear and co-pilot positions) cars; the proportion of using child safety seats (including those installed in the rear and co-pilot positions) is only $11.5 \%$. compared with over $90 \%$ of the usage rate child safety seats of developed countries such as Europe and the United States, the usage rate child safety seats of China is significantly lower ${ }^{[2]}$.

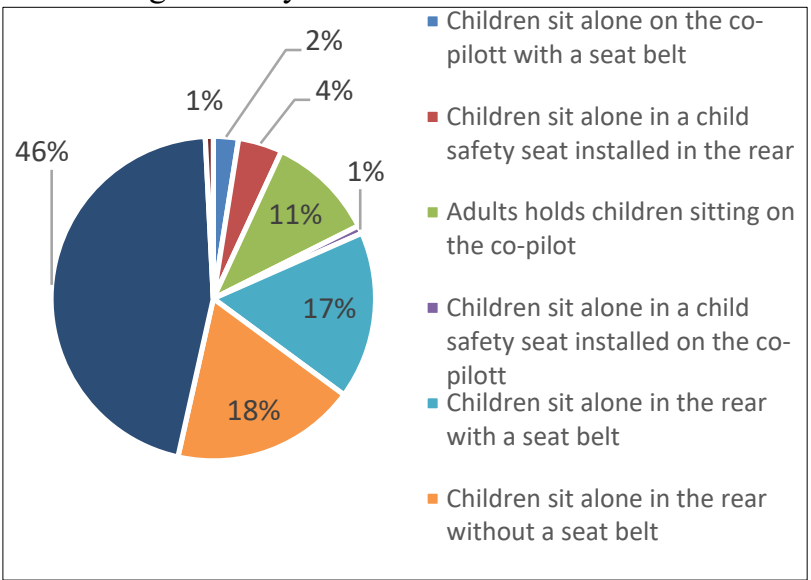

Figure 2: The proportion of children taking private car in different ways

\section{Classification of child safety seats}

\subsection{Classification according to installation method}

Existing child safety seats can be roughly divided into three categories according to the different installation methods: traditional car seat belts fixed type, European standard ISOFIX fixed type, American standard LATCH fixed type. In addition, there are some additional Fixed methods that cannot be used alone, such as pedal support and Top Tether fixation.

Table 1: different installation methods

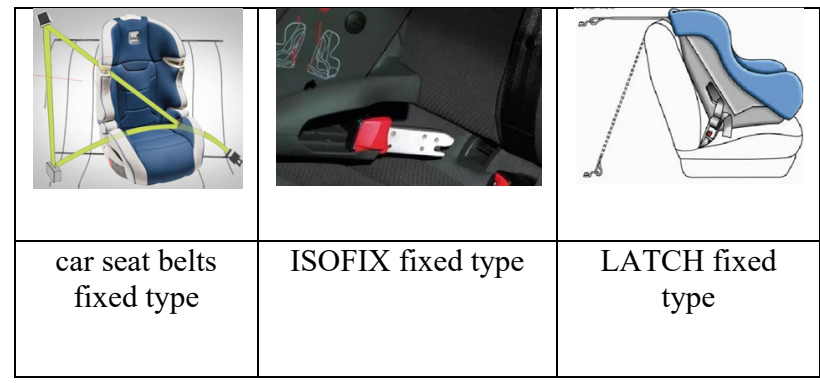

\subsection{Classification according to children's height and weight}

1. Child safety seats are classified according to the age of children, which can be mainly divided into: infant type (for children aged 0 to 1 year old); toddler type (for children aged 1 to 4 years old); school children type (for children aged 4 to 8 years old); increased type (for children aged 8 to 12 years old)

2. The European ECE-R44 standard is classified by the size of the child's weight, including four categories: when the child's weight is less than $10 \mathrm{~kg}$, you can choose the 0 group; when the child's weight is less than $13 \mathrm{~kg}$, you can choose the $0+$ group; when the child's weight is 15 Group II can be selected within the range of $\mathrm{kg}$ to $25 \mathrm{~kg}$; group III can be selected when the child's weight is within the range of $22 \mathrm{~kg}$ to $36 \mathrm{~kg}$.

\subsection{Classification in a fixed way}

When a car is in a violent collision, it will produce a strong impact force, fixing the body of the user who rushes out quickly, so that the user will not be thrown out, and reducing the impact force is an important guarantee for the user's life safety. At present, the fixed child safety devices are divided into three categories: five-point seat belts type, three-point seat belts type and front-guard type.

Table 2: different way of fixing childrens' body

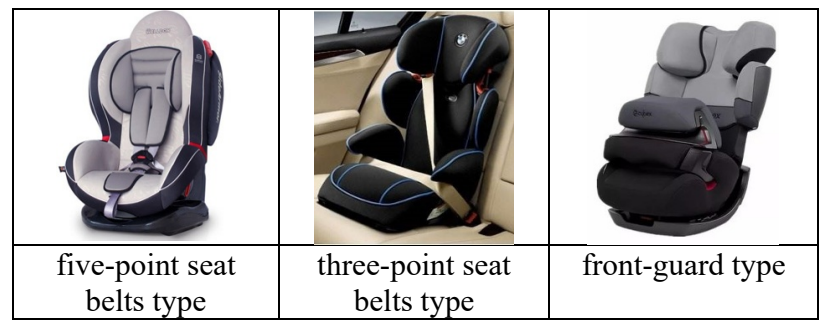

\section{Design principles and positioning}

The design of this child safety seat follows the following basic principles: safety principles, functional principles, aesthetic principles, economic principles, environmental protection principles, etc. 
Set the user population as children aged 0-12 years old and weighing $0-36 \mathrm{~kg}$, and design a child safety seat that can be adjusted to adapt to the body shape of children of different ages under ergonomic conditions. The main consumers are the parents of middle-income families.

\section{Analysis of children's physical and psychological demands}

\subsection{The physical characteristics of children}

The design of this child safety seat follows the following basic principles: safety principles, functional principles, aesthetic principles, economic principles, environmental protection principles, etc.

Designing a good product is not only to focus on the function and appearance, but also to conform to the human characteristics as the starting point, and fully consider the user's experience in use and even after use. The main research objects of this subject are children from 0 to 12 years old who fit into the child safety seat. Children are the main users of the product. In addition to considering the safety of the child safety seat, the design must also be developed around the child's physical and psychological characteristics.

Children's physiological characteristics are different from adults, so children's products are different from adults' products in terms of size, operation methods, and inspection standards. Children are in the growth and development stage, and their body shapes have not been completely finalized. It is necessary to design child safety seats that meet the ergonomic size of children of different ages within a certain range.

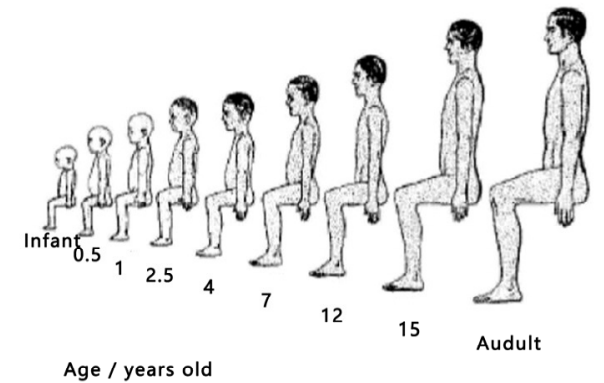

Figure 3: The length of the body trunk changes with age when sitting

The design of a child safety seat that is suitable for the child's body shape and is comfortable to ride and lie on must be based on a large number of measured data of various body parts of the child in various postures. It is used to complete the design of key aspects such as the height of the chair surface, the width of the chair surface, the depth of the chair surface, the inclination of the chair surface, the height and width of the backrest, and the height of the armrest. According to the data given in GB/T 26158-2010 "Chinese Minor Body Dimensions", this topic selects some key data for design practice.

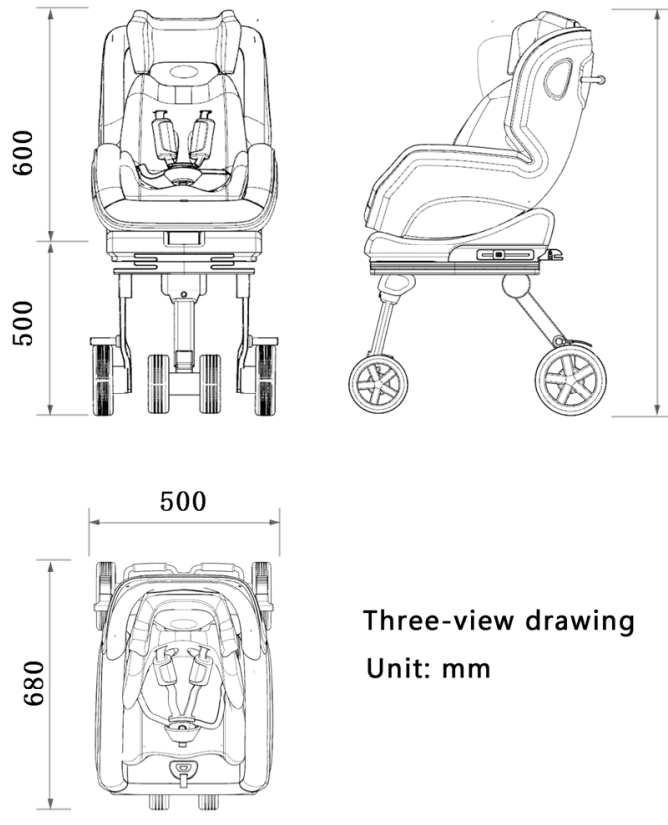

Figure 4: Three views and partial dimensions of the product

After a large amount of data analysis and research, with an appropriate amount of correction, set the height of the child safety seat to $500 \mathrm{~mm}$; the width of the seat is $360 \mathrm{~mm}$; the depth of the seat is $400 \mathrm{~mm}$; the three inclinationangles of the seat are: $110^{\circ}, 135^{\circ}, 160^{\circ}$, respectively suitable for children's sitting, reclining and lying; the width of the backrest is $500 \mathrm{~mm}$; the height of the backrest can be adjusted in the range of $500 \mathrm{~mm}-700 \mathrm{~mm}$; the height of the armrest is $15 \mathrm{~mm}$.

\subsection{The psychological characteristics of children}

With the development of body and intelligence, children's psychology is also developing. Making good use of children's psychological characteristics and under the guidance of design psychology to design child safety seats that meet children's psychological needs of function, use, and aesthetics.

\subsubsection{Children and their functional psychological needs analysis.}

Function is the purpose of the product, and it is the decision factor of industrial design ${ }^{[3]}$. The function of the product is the foundation for the survival of the product. The general product design is based on the product function as the design demand orientation. Function is relative to human needs, and needs reflect human inner psychological activities. For the design of children's products, the psychological needs of children for functions should also be met. Firstly, the function should be advanced. Advanced products are relative. They can be some new designs, or the improvement and development of old things. This design work is to improve the function of the old child safety seat.

Secondly, the range of functions should be reasonable. Modern people's pursuit of products tends to be multi- 
functional- various functions are integrated. However, sometimes the multi-function may turn the cart before the horse, focusing on additional functions while ignoring the main functions, or the cost increase due to redundant functions. Therefore, this design must be diversified under the precondition of ensuring excellent main functions. Finally, the performance of the work should be excellent, and the quality must be good. The satisfaction of these requirements can enable people to meet their functional psychological needs, and can also be used to guide the design of children's products.

\subsubsection{Children and their use psychological needs analysis.}

First of all, the first element of the use of child safety seats is to ensure the safety of its performance. It should give people a sense of safety when using it. A reasonable design can reduce the psychological irritability and rejection of children during use and improve their interest and safety. secondly, a good product is easy to understand in use and not easy to misuse. Children's products should meet the psychological needs of children to prevent potential safety hazards caused by misoperation. Curious, hyperactivity and restlessness are the typical characteristics of children's psychology. Children are easy to twist around or play with the parts of the seat during the use of child safety seats. Therefore, the child safety seat should be designed to avoid dangers caused by children touching parts during use.

\subsubsection{Children and their aesthetic psychological needs analysis.}

Generally speaking, aesthetic ability is a kind of ordinary perception ability that a person is born with through inheritance, and can be gradually developed through acquired environment and education. Aesthetics is a process of continuous development. Aesthetics in childhood is simple and limited, and can only appreciate simple artistic beauty and natural beauty. Therefore, children's aesthetic standards for products are different from those of adults. The aesthetic perception of products is based on human emotions. Aesthetic feeling is directly derived from the perceptual perception and representation of the shape, color and texture of the product appearance, and is the result of various psychological activities such as perception, understanding, imagination and emotion ${ }^{[4]}$. Children's perception of the outside world is concrete, intuitive and perceptual. Children's most intuitive perception of products comes from the color of the product. Good color matching is the first step to attract children's attention and stimulate parents' desire to buy. According to investigations and studies, children prefer bright, rich, and contrasting colors. Therefore, a good grasp of the cool and heating applications and symbolic applications of colors in the design of child safety seats helps to better meet the psychological needs of children. In addition, the shape and texture of the product are also key issues that should be considered in the appearance design. Compare with the appearance of hard, sharp and cold products, children's products should be round, harmless and lively that meet the aesthetic needs of children.

\section{Product design outputs}

\subsection{The description of product}

The highlight of this research is that the product can be easily converted between child safety seats, children's dining cars, and baby strollers, so that one product can meet multiple needs of users. It grasps the pain point that parents must carry relatively large and inconvenient children's products such as strollers, baby dining chairs, and child safety seats when traveling with children. Indepth analysis of the feasibility of integrated child products used in multiple scenarios, established the concept of multi-functional child safety seats, and designed a child safety seat under the premise of ensuring safety, which can be used in cars, restaurants without children's dining chairs, and short walks.
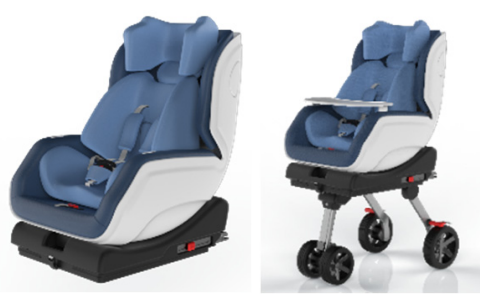

Figure 5: display of product renderings

\subsection{The structure of product}
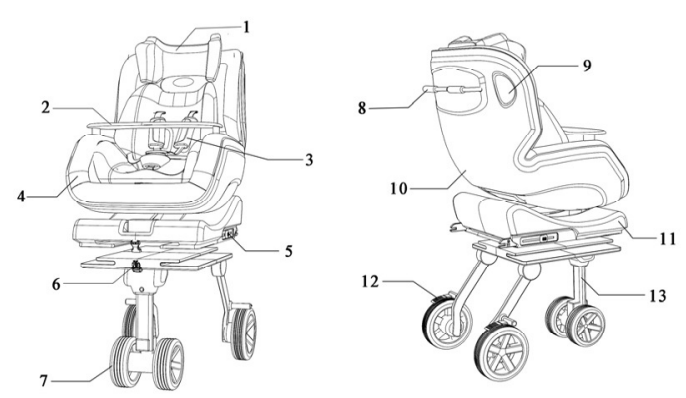

Figure 6: diagram of product structure

The marks in the picture are: 1 adjustable headrest, 2 detachable table top, 3 five-point safety belt, 4 soft cushion, 5 ISOFIX hard link system, 6 fixed insert fasteners, 7 universal wheels, 8 stretch type armrests, 9 side wing anticollision devices, 10 hard shells, 11 bases, 12 brake systems, 13 folding brackets.

\subsection{The material and color matching of product}

This multifunctional child safety seat is composed of a seat shell, a cushion and a base frame. The main material of the hardware part is a hard and firm carbon alloy steel frame as the skeleton, and the outer shell is injection-molded PP (polypropylene). The main material of the soft part is EPS (polystyrene foam), EPP (expanded polypropylene), EPE (polyethylene foam), etc., which have good cushioning 
and energy absorption properties, which can fully relieve the impact resistance and effectively provide protection for children. The base frame is made of aluminum alloy with high mechanical strength and surface hardness, which still maintains the inherent characteristics of low aluminum density. It can not only support well, but also is lighter and more portable.

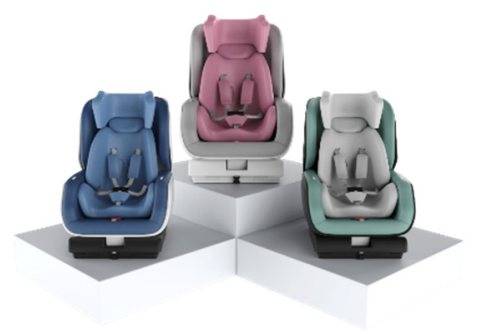

Figure 7: Product color scheme

Excellent color matching is the first step to attract children, and bright and lively colors can attract children's attention and be loved. Blue symbolizes calmness, rationality and strength, giving people a sense of security; green represents nature and innocence; pink is dreamy and romantic, and it is the "princess color" preferred by girls. Therefore, the product adopts blue, green and pink as the main colors

\subsection{The Product installation}

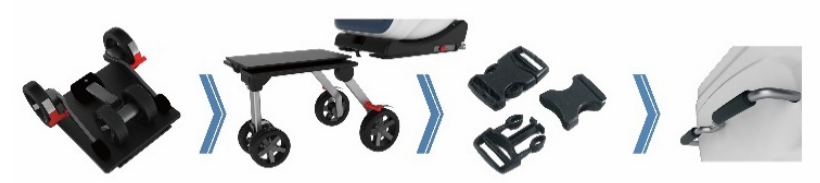

Figure 8: The schematic diagram of converting a child safety seat into a stroller

Operation steps:

Step1.unfold the base bracket

Step2. insert the bottom bracket into the child safety seat base

Step3.buckle the fasteners

Step4. pull out the rear armrest of the seat

The child safety seat can be converted into a stroller.

\section{Conclusion}

Standing on the shoulders of the predecessors, this subject research conducted a more in-depth research, exploration and design improvement of existing child safety seats on the market. Faced with the insufficiency of the low purchase rate and low utilization rate of the existing child safety seats, the reason analysis was put forward through data review and user research. And select the two important reasons that hinder consumers from buying child safety seats in conclusion: single function and unsightly appearance to improve the design, which will help the development of child safety seat design and meet more needs of users. It has certain guiding significance for the development of related products.

\section{REFERENCES}

1. McNeil, 2003 Kids Marketing. Zhang, H.X, trans. Huaxia Publishing House, Beijing, China.

2. Pan, R.L and Xue, J and Hu, y (2017). Investigation and current situation analysis of the use of child safety seats in China. Auto Industry Research, 22-25.

3. Yang, H.B(1995). On the basic principles and elements of industrial design. Mechanical Design, 45 (5), 42-43.

4. Tong, S.Z(2000). On the psychology of product design. mechatronic engineering, 02, 38-44.

5. Gao, Y.Y(2010). Domestic reference European car child safety mandatory standards. Pacific Car Parenting Hotspot.

6. Cui, S.L(1989). The development of car seat belts. Foreign Cars, 01, 53-57.

7. Hu, J and Zhong, Z.H .2008. Research on frontal and side impact safety of child occupants based on experiments and finite element simulation. Hunan university, Changsha.

8. He, X.Y and Xie, Y, F, 2001 Humanization Design. Jiangsu Fine Arts Publishing House, Jiangsu, China. 